\title{
Prediction of Cavity Growth in Underground Coal Gasification Using Differential Evolution
}

\author{
B. Pradeep Santhosh Kumar ${ }^{1}$, P. Hari Babu ${ }^{2}$, M.Koteswararao ${ }^{3}$, M.Shivanaresh ${ }^{4}$ \\ ${ }_{1,3,4}^{4}$ Department of Chemical Engineering, ANITS, Vishakapatnam 531162, India \\ ${ }^{2}$ Department of Chemical Engineering, Rajiv Gandhi University of Knowledge Technologies, Basar, 504 107, India \\ *Correspondence: Faculty, Department of Chemical Engineering, ANITS, Vishakapatnam, 531162, India ${ }^{1}$ \\ Email: pradeep.che@anits.edu.in ${ }^{1}$,santosh.bps@gmail.com ${ }^{2}$
}

\begin{abstract}
Due to increase in global concern all over the world, there comes the need for using safer and cleaner technologies for production of energy. Many of coal reserves all over the world are very difficult to be exploited by conventional coal tapping methods. Underground coal gasification is successful in tapping such un-mineable coal reserves. The main advantages in adapting UCG are it yields lesser amount of wastes, is more economical, safer compared to all other conventional methods. During the process of coal gasification, a cavity is formed underground which consists of coal, char, ash, rubble, and void space. The shape of the cavity and the cavity growth are very important because they are the underlying factors in optimal utilization of coal reserves. The dimensions of the cavity are of utmost importance because they are crucial in efficient usage coal resources and their recovery. Based on the data obtained from the laboratory scale experiments conducted on coal blocks, influence of different parameters on growth of the cavity volume can be deduced. Predictions of the cavity growth rate, estimates how efficiently one can use the coal reserves. Differential Evolution technique has proved its usefulness in the field of signal processing. Usefulness of Differential Evolution is applied in this current work to determine the relationship between cavity dimensions and distance between the wells, flow rate of inlet combustion mixture, time of operation.
\end{abstract}

Key Words: Syngas, Cavity, Injection well, and Differential Evolution.

\section{INTRODUCTION}

\subsection{History}

Coal has been the one of the major sources for energy production. There has been a vast distribution of coal reserves all over the world as well as India. Only 1/6th of the world's coal reserves are economically accessible by conventional methodologies. The major drawback in using conventional coal technology is the wide variety of pollutant gases generated during the process. This reduces the quality of air as well as water. The coal industry uses the expression 'Clean Coal Technologies' to describe processes and techniques designed to enhance both the efficiency and the environmental acceptability of coal extraction and processing, with reduced emissions of carbon dioxide. These efforts include chemically washing minerals and impurities from the coal during direct power generation, conventional coal gasification and coal direct or indirect liquefaction processes; and treating the gaseous combustion products (flue gases) to remove sulfur dioxide $\left(\mathrm{SO}_{2}\right)$ and capture carbon dioxide $\left(\mathrm{CO}_{2}\right)$. Underground Coal Gasification (UCG) is one of such clean coal technologies which replaces the conventional combustion process by gasification of coal.

\subsection{Introduction to $U C G$}

Underground Coal Gasification (UGC) is an alternative method for surface gasifiers. In this method coal is converted to syngas with considerable amounts of thermal energy in-situ. This process involves burning coal underground with mixture of air/oxygen and steam. If the process is developed commercially, it would increase coal reserves by $60 \%$. Even if $10 \%$ of this potential is met, it would provide a significant amount of additional energy source.

However, UCG introduces some challenges that should be addressed before the process can be adopted in large scale. UCG process usually consumes water contained in the coal seam and adjacent strata. Also, water can be pumped as steam, along with air or oxygen, into the injection well. In any case, some amount of water will remain unreacted, which potentially can lead to contamination of groundwater by harmful byproducts of the UCG process. To avoid this, environmental monitoring during and after the UCG process needs to be conducted; other challenges are process stability, and subsidence. The UCG performance is largely affected by properties of the coal seam, geological and hydrogeological conditions of the site which make prediction of UCG performance more difficult.

UCG is based on a system of injection-production wells that makes possible the in situ conversion of coal into syngas by a physicochemical process. In UCG technology, the in-situ coal is not subjected to cleaning or preparation stages as in the conventional gasification process, so a good understanding of the in situ coal properties and coal calorific value is required. Syngas generated during UCG is further utilized in energy production.

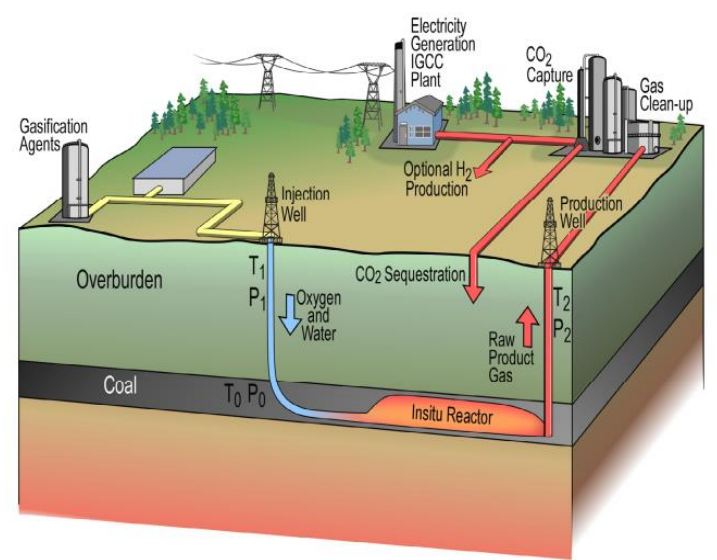

Figure 1.2.1 shows the concept of UCG power generation. 


\section{International Journal of Research in Advent Technology, Vol.7, No.4, April 2019 E-ISSN: 2321-9637 \\ Available online at www.ijrat.org}

\subsection{Advantages and significance of UGC}

1. Can tap coal reserves which are difficult to exploit with conventional methodology

2. Can bring down the capital costs as it obviates mining, transportation costs

3. Low grade coals can be tapped for energy recovery in an economical way

4. More work safety, few wastes to be disposed of

5. Potential towards carbon capture \& sequestration

\subsection{Syngas and its Properties}

The produced syngas is a mixture of mainly carbon monoxide and hydrogen, which can be used as fuel for power generation and feedstock for various chemical products (i.e., hydrogen and ammonia). Emissions from syngas combustion are generally cleaner and may produce less greenhouse gas emissions than coal-fired facilities. The heating value of the produced syngas can be increased by oxygen enrichment of the injected air. A decrease in the seam thickness can reduce the heating value of the produced gas, which is associated with heat loss to the surrounding formation. Typical Components of UGC are $\mathrm{CO}, \mathrm{CO}_{2}, \mathrm{H}_{2}$, $\mathrm{CH}_{4}$, and $\mathrm{H}_{2} \mathrm{~S}$. The composition of Syngas from UCG can vary substantially depending on the injected oxidant used, operating pressure. The temperature and pressures of the produced gas depends on the type of the coal seam.

\section{Worldwide development and application of UGC}

The potential for UCG to access low grade, inaccessible coal resources and convert them commercially and, competitively into syngas is enormous, with potential applications in power, fuel, and chemical production. Demand for lower greenhouse-gas emissions from coal-fired power generation, a shift toward gas as a preferred fuel and a reviving interest in the production of synthetic fuels are the favorable combination of factors that has provided the opportunity for the process to become commercially viable by optimizing the technological parameters and also reducing the impact on the environment. UCG research and development have been conducted in several countries, including long-term commercial operation of several UCG plants in the former Soviet Union. Over 50 pilot UCG plants have been conducted worldwide since the 1930s [2]

The first recorded proposal of Sir William Siemens, a German scientist, suggested underground coal gasification in 1868, followed by Mendeleyev 20 years later [2].USSR may be considered the first nation to heavily engage in UCG. National research programs on UCG have been undertaken during the past 80 years in the former Soviet Union and since the 1980s by Western Europe, the United States, China, India and Australia. Till date, industrial-scale UCG applications in the Soviet Union have gasified more than 17 million tones of underground coal [4]

Some of the well-documented UCG operations are those at Angren-Uzbekistan, Queensland-Australia, Alberta-Canada, Walanchabi City-China, and Majuba-South Africa. The most advanced UCG operation is at Chinchilla in Queensland, Australia, where the operator claims to be generating electricity from UCG product gas at a highly competitive cost. Belgium developed the method of linking wells by continuous retraction injection point or reverse combustion (CRIP) for deep coal seams which is now one of the technologies in widespread use. Queensland, known as the Blue Gum Energy Park, is also in the early stages of planning. Swan Hills Synfuels recently produced syngas from its pilot project in Alberta, Canada. This project is the deepest UCG pilot ever undertaken, at a depth of $1400 \mathrm{~m}$, and is using the linear controlled retractable injection point method. The ENN Group Co. Ltd. produced syngas from a pilot project in Walanchabi City, Inner Mongolia, China, for 26 months, gasifying more than 100,000 tons of coal [2]. Figure 1.5.1 illustrates the current world-wide status of the technology.

UCG is a promising technology for India, which has vast coal resources, primarily of low grade. India looks to utilize its coal reserves, which are the fourth-largest in the world,to reduce dependency on oil and gas imports. UCG is expected to be used to tap India's coal reserves, which are difficult to extract economically using conventional technologies. The Oil and Natural Gas Corporation Ltd. (ONGC) is planning to carry out pilot projects using recommendations of experts from the Skochinsky Institute of Mining in Moscow.The Gas Authority of India Ltd. (GAIL) and AE Coal Technologies India Pvt. Limited, a company belonging to the Abhijeet Group of India,are implementing UCG projects using Ergo Exergy's UCG technology. Recently, computational fluid dynamics studies of complex flow patterns in a growing UCG cavity were conducted by researchers of IIT-Bombay in collaboration with ONGC. The main objective of this work was to understand the velocity distribution and perform residence time distribution (RTD) studies in the UCG cavity. Based on the RTD studies, the actual UCG cavity at different times was modeled as a simplified network of ideal reactors, which might offer a computationally less expensive and easier option to determine UCG process performance as a function of time [3].

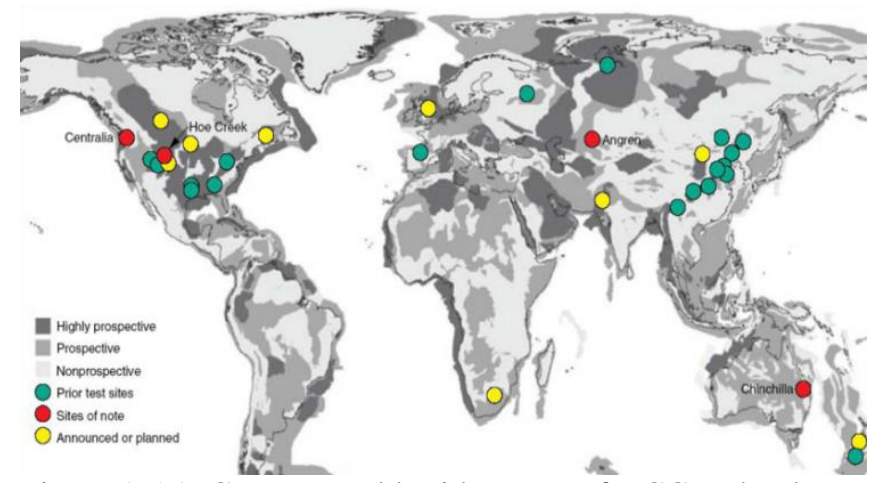

Figure 1.5.1: Current world-wide status of UCG technology

\section{UCG PROCESS OVERVIEW}

A typical UCG process consists of injection and production wells drilled into a coal seam. The coal is ignited using LPG. It is followed by injection of air and/or oxygen. Chemical reactions convert the coal to syngas by pyrolysis, combustion and gasification reactions. The main UCG byproducts are roof-rock fragments and ash-rubble in the void space underground, flue gases and fly-ash, both entrained in the syngas stream, which are subsequently collected and processed further for the production of energy (as a part of the power or chemical plant system). Figure 2.1 shows typical UCG process. UCG involves 3 major steps. They are Well \& Link Establishment, Coal seam Ignition \& Gasification and Site Clean-up 


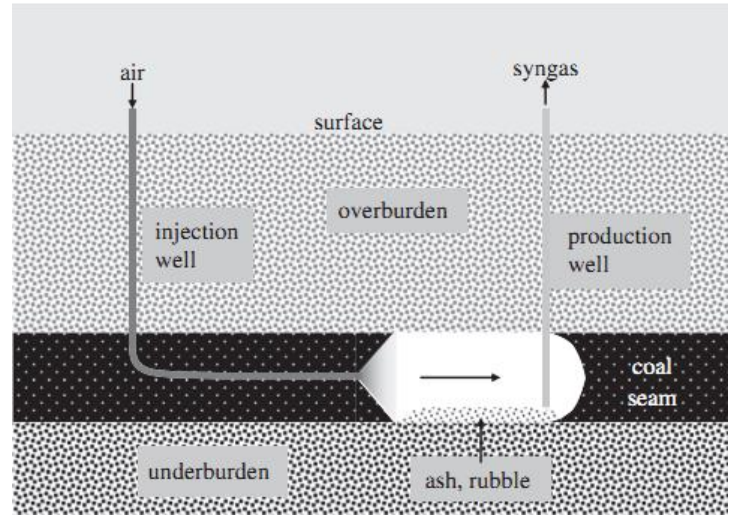

Figure 2.2: Underground Coal Gasification Process

\subsection{Well and Link Establishment}

In the well establishment step, injection and production wells should be drilled from surface to the coal seam. The basic layout of the process requires one borehole for injection of gases and one for production, however over the years three standard configurations of wells have been evolved which are Linked Vertical Wells (LVW), Controlled Retraction Injection Point (CRIP), Steeply Dipping Seams (SDS).

The LVW configuration is based on the Soviet Union field trials and involves two wells that are connected by a linking method. It involves a movable injection point that is retracted when coal seam around the point is consumed. Gases will come in contact with coal when the liner is burnt away by ignition. This method provides greater control over gasification reactor, improves resource recovery, and requires comparatively fewer wells. Two variations of the CRIP technology have been practiced over the years. Linear CRIP in which a number of cavities are formed in series and parallel CRIP in which the cavity continuously grows along the coal until the whole coal seam is consumed. To apply UCG in steep dipping seams (dip angle $>50^{\circ}$ ), inclined injection should be used. In this method, injection well is drilled in lower part of the seam and production well is located in lower third of coal. In horizontal coal seams, inert roof material falls and remains unreacted as gases tend to move upward; while in steeply dipping seams, more char is accumulated around injection well that results in improved quality of produced gas (oxidation zone remains close to injection well, while reduction and pyrolysis zone would extend along the path of gas.). Few trials performed on SDB which resulted in higher gas qualities compared to horizontal seams. However, this method can only be conducted in certain seams and control of the process is a major challenge for this method. Furthermore, the difference in hydrostatic pressure along the seam makes it hard to control the ground water flow into the cavity[1]

Since initial permeability of the coal seam does not allow sufficient gas flow for operation at large scale, a link which is a permeable path between injection and production wells should be established prior to start of gasification phase. Main methods for linking include Forward Combustion Linking (FCL), Reverse Combustion Linking (RCL), Hydro-Cracking, Electro Linking,
Explosive Linking, and Inseam Linking. Of all the techniques, the prominent ones are FCL \& RCL.

$\boldsymbol{R C L}$ : It is a method of linking in which oxidant is injected into the injection well and coal is ignited in the production well, so that combustion propagates toward the source of oxidant.

$\boldsymbol{F C L}$ : It is a method of linking in which ignition is done in the injection well, and the fire propagates toward the production well [2].

\subsection{Ignition and Gasification}

Link Establishment is followed by ignition. Igniting the coal is necessary for initiation of UCG process. There are little reliable data on ignition methods for UCG in open literature. Various methods of ignition that have been used in trials include use of pyrophoric compounds such as silane and triethylborane (TEB), methane or propane gas, electrical ignition, dropping hot coke down the well, and spontaneous combustion of coal with pressurized oxygen. The only detailed description for ignition process is from large block experiments in which mixture of silane and propane was used. Driving forces for gasification are permeability of coal seam and buoyancy forces.

Gasification: The phenomena in which a mixture of air or oxygen and steam is passed through injection well and chemically made to react with coal to generate thermally energized SYNGAS which can be recovered from production well.

Syngas may be processed further for the $\mathrm{CO}_{2}$ capture \& sequestration, $\mathrm{CO}$ removal. Quality of syngas is controlled by varying the injection levels of air/steam mixture. As a part of the gasification, underground cavity formation takes place. Water from the surroundings of coal seam enters the cavity and starts participating in the reaction (as a result level of water table drops). Exhaustion of coal in the accessibility of injection well takes place after sometime. To sustain syngas production step 1 and step 2 are repeated until the entire coal seam is efficiently utilized [2].

\subsection{Site cleanup}

Gasification is then followed by site clean-up. The essence of this step is to bring back the environmental balance. Flushing of cavities with steam/water is done to free the coal seam from pollutants. It also helps in bringing back the water table back to its original level prior to gasification [2]

\subsection{Coal Gasification Reactions}

Gasification result primarily in a gaseous mixture of $\mathrm{CO}, \mathrm{H}_{2}$ and $\mathrm{CH}_{4}$. In both conventional and UCG processes, the chemical and physical changes are similar, however, the in situ coal naturally has higher methane and moisture contents than does the coal feedstock for conventional coal gasification. In coal gasification, four principal reactions are crucial which are mentioned as follows.

Steam Gasification: The steam gasification reaction is endothermic, i.e., requiring heat input for the reaction to proceed in its forward direction.

$\mathrm{C}+\mathrm{H}_{2} \mathrm{O} \rightarrow \mathrm{CO}+\mathrm{H}_{2}$

Carbon dioxide gasification: Carbon dioxide reacts with carbon to produce carbon monoxide and this reaction is called Boudouard reaction. This reaction is also 
endothermic in nature, similar to the steam gasification reaction.

$\mathrm{C}+\mathrm{CO}_{2} \rightarrow 2 \mathrm{CO}$

Hydrogasification: Direct addition of hydrogen to coal under high pressure forms methane. This reaction is called hydrogasification. This reaction is exothermic and is thermodynamically favored at low temperatures, unlike both steam and CO2 gasification reactions

$\mathrm{C}+2 \mathrm{H}_{2} \rightarrow \mathrm{CH}_{4}$

Partial Oxidation reaction: Combustion of coal involves reaction with oxygen, which may be supplied as pure oxygen or as air, and forms carbon monoxide and carbon dioxide.

$\mathrm{C}+\mathrm{O}_{2} \rightarrow \mathrm{CO}_{2}$

$\mathrm{CO}+1 / 2 \mathrm{O}_{2} \rightarrow \mathrm{CO}_{2}$

During the combustion drying, pyrolysis and gasification of char occur. Gasification reactions occur both in the solid and the gaseous phases as well as on their boundaries [8]

\subsection{Classification of Gasification Zone}

Based on the differences in major chemical reactions, the temperature, and the gas compositions, the gasification channel can be divided into three zones: Oxidization zone, Reduction zone and Dry distillation zone. Figure 2.5.1 depicts the various zones formed during the coal gasification process.

\subsubsection{Oxidation Zone}

In this zone, exothermic chemical reactions between oxygen and carbon in the coal seam occur. Temperatures in this zone range from $900-1450^{\circ} \mathrm{C}$. As oxygen burns out gradually, the air stream gets into the reduction zone

\subsubsection{Reduction Zone}

In this zone $\mathrm{H}_{2} \mathrm{O}$ and $\mathrm{CO}_{2}$ are reduced to $\mathrm{H}_{2}$ and $\mathrm{CO}$ under the effect of high temperatures \& pressure ranging from $600-1000{ }^{\circ} \mathrm{C} \& 0.01-0.2 \mathrm{MPa}$ respectively. Additionally under the catalytic action of coal ash \& metallic oxides methanation occurs. All the reactions occurring in the reduction zone are endothermic, thereby lowering the zone's temperature.

\subsubsection{Distillation Zone}

In this zone, temperatures range about $\left(200-600{ }^{\circ} \mathrm{C}\right)$. Different compounds are distilled out at different temperatures. When the temperature in this zone falls below $300{ }^{\circ} \mathrm{C}$, small amounts of paraffin's, water and $\mathrm{CO}_{2}$ will start separating out. As the temperature exceeds $300{ }^{\circ} \mathrm{C}$, polymerization occurs. When the temperature is in the range of $\left(350-550{ }^{\circ} \mathrm{C}\right)$, tar oil \& combustible gas will be separated out. At temperatures of above $550{ }^{\circ} \mathrm{C}$, semi-coke remains start contracting and will solidify; yielding $\mathrm{CO}_{2}, \mathrm{H}_{2}$ \& $\mathrm{CH}_{4}$.Proportion of contents of the product gas varies from one gasification agent and air injection method to another.

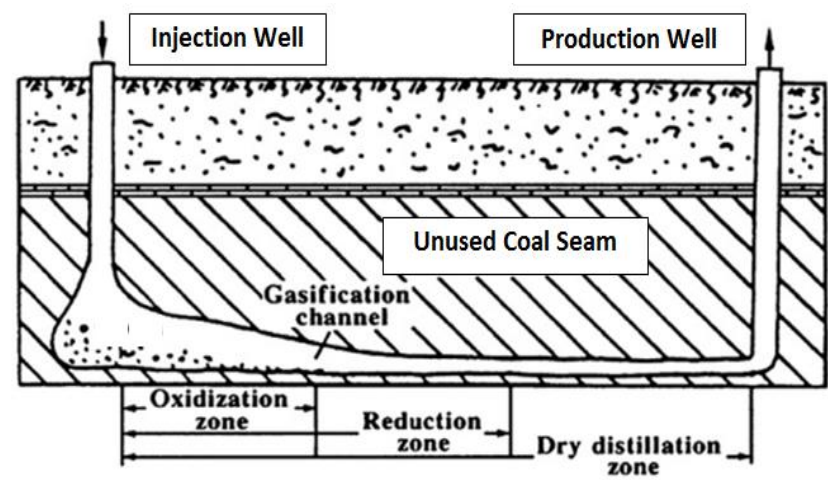

Figure 2.5.1: Classification of Gasification Zone

\section{THEORETICAL STUDIES ON UGC EXPERIMENTS}

3.1 Experiments on Coal Blocks

The samples of lignite coal blocks are obtained from Gujarat Industries Power Company limited, INDIA (GIPCL). Injection and production wells are drilled from top surface to bottom of the coal samples each of $3 \mathrm{~mm}$ in diameter. A link is established between the two wells by making a horizontal gasification channel of $3 \mathrm{~mm}$ diameter at the bottom surface of coal sample. The coal block is covered with refractory bricks and sealed with the help of a sealing material, Accoset-50 (i.e. high temperature cement) to avoid leakage from the reactor. In all the experiments, the coal block width and height are kept constant and only the length is varied in order to study the effect of the distance between the two wells. The results of proximate and ultimate analyses of the coal samples are given in Table 3.1\& 3.2 respectively.

\begin{tabular}{|l|l|}
\hline \multicolumn{2}{|l|}{ Proximate Analysis } \\
\hline Component & $\%$ Composition \\
\hline Moisture & 40 \\
\hline Volatile Matter & 11 \\
\hline Fixed Carbon & 44 \\
\hline Ash & 5 \\
\hline
\end{tabular}

Table 3.1 : Proximate Analysis of Coal Block

\begin{tabular}{|l|l|}
\hline \multicolumn{2}{|l|}{ Ultimate Analysis } \\
\hline Component & \% Composition \\
\hline Carbon & 60.366 \\
\hline Hydrogen & 4.367 \\
\hline
\end{tabular}

Table 3.2 : Ultimate Analysis of Coal Block 
The experimental set-up and procedure is described elsewhere (Sateesh Daggupati et al., 2010). After completion of the experiment, the coal block is allowed to cool for approximately $6 \mathrm{~h}$ and it is separated from the refractory bricks in order to capture the final cavity shape with the help of molten wax. The final cavity dimensions in all the directions are measured. The coal block dimensions and operating conditions are given in Table 3.3.The distance between the injection and production wells $\left(D_{w}\right)$, reactant gas flow rate $(\mathrm{Q})$ and total operation time $(\mathrm{t})$ are the chosen parameters, and their influence on the evolution of the cavity is analyzed. A total of 27 runs were performed on the lignite coal samples by varying the feed flow rate, operation time and distance between the two wells (Sateesh Daggupati et al., 2010). The data generated can be used further to obtain the evolution of the gasification cavity. The final cavity dimensions in all the directions and the corresponding cavity volumes, for all the experiments, are given in Table 3.4.

\begin{tabular}{|l|l|}
\hline \multicolumn{2}{|l|}{ Coal Block Dimensions } \\
\hline Width $(\mathrm{cm})$ & 20 \\
\hline Height $(\mathrm{cm})$ & 25 \\
\hline Length $(\mathrm{cm})$ & $16,20,24,28$ \\
\hline Operating Conditions \\
\hline Flow rate $(\mathrm{ml} / \mathrm{min})$ & $800,1000,1250$ \\
\hline Operating time $(\mathrm{hr})$ & $10,12,14,16$ \\
\hline
\end{tabular}

Table 3.3 : Coal Block dimensions and Operating

Conditions

\begin{tabular}{|c|c|c|c|c|c|c|c|c|}
\hline $\begin{array}{l}\text { S.N } \\
\text { o }\end{array}$ & $\begin{array}{l}\mathbf{D} \\
(\mathbf{c} \\
\mathbf{m})\end{array}$ & $\begin{array}{l}\text { Q } \\
\text { (cc/mi } \\
\text { n) }\end{array}$ & $\begin{array}{l}\mathbf{t} \\
\text { (mi } \\
\text { n) }\end{array}$ & $\begin{array}{l}\mathbf{F}_{1} \\
(\mathbf{c} \\
\mathbf{m}) \\
\end{array}$ & $\begin{array}{l}\mathbf{B}_{1} \\
(\mathbf{c} \\
\mathbf{m}) \\
\end{array}$ & $\begin{array}{l}\text { W } \\
\text { (c } \\
\text { m) }\end{array}$ & $\begin{array}{l}\mathbf{H} \\
(\mathbf{c} \\
\mathbf{m}) \\
\end{array}$ & $\begin{array}{l}\mathrm{C}_{\mathrm{v}} \\
\text { (cc) }\end{array}$ \\
\hline 1 & 16 & 800 & 600 & $\begin{array}{l}14 . \\
2\end{array}$ & 5 & $\begin{array}{l}11 . \\
8\end{array}$ & 7.9 & 500 \\
\hline 2 & 16 & 800 & 720 & $\begin{array}{l}15 . \\
8\end{array}$ & 5.4 & $\begin{array}{l}12 . \\
4\end{array}$ & 8.8 & 645 \\
\hline 3 & 16 & 800 & 840 & $\begin{array}{l}17 . \\
5\end{array}$ & 5.9 & $\begin{array}{l}13 . \\
2\end{array}$ & 9.7 & 780 \\
\hline 4 & 16 & 1000 & 600 & $\begin{array}{l}16 . \\
2\end{array}$ & 5.2 & $\begin{array}{l}12 . \\
8\end{array}$ & 8.7 & 620 \\
\hline 5 & 16 & 1000 & 720 & $\begin{array}{l}18 . \\
2\end{array}$ & 5.7 & $\begin{array}{l}13 . \\
5\end{array}$ & 9.7 & 780 \\
\hline 6 & 16 & 1000 & 840 & $\begin{array}{l}20 . \\
3\end{array}$ & 6.2 & $\begin{array}{l}14 . \\
2\end{array}$ & $\begin{array}{l}10 . \\
7\end{array}$ & 965 \\
\hline 7 & 16 & 1250 & 600 & $\begin{array}{l}18 . \\
6\end{array}$ & 5.6 & 14 & 9.6 & 755 \\
\hline 8 & 16 & 1250 & 720 & 21 & 6.1 & $\begin{array}{l}14 . \\
8\end{array}$ & $\begin{array}{l}10 . \\
7\end{array}$ & 940 \\
\hline 9 & 16 & 1250 & 840 & 24 & 6.6 & $\begin{array}{l}15 . \\
5\end{array}$ & $\begin{array}{l}11 . \\
8\end{array}$ & $\begin{array}{l}115 \\
0\end{array}$ \\
\hline 10 & 20 & 800 & 600 & $\begin{array}{l}13 . \\
7\end{array}$ & 4.9 & $\begin{array}{l}12 . \\
8\end{array}$ & 8.7 & 470 \\
\hline 11 & 20 & 800 & 720 & $\begin{array}{l}15 . \\
3\end{array}$ & 5.3 & $\begin{array}{l}13 . \\
5\end{array}$ & 9.7 & 600 \\
\hline 12 & 20 & 800 & 840 & $\begin{array}{l}16 . \\
9\end{array}$ & 5.8 & $\begin{array}{l}14 . \\
2\end{array}$ & $\begin{array}{l}10 . \\
7\end{array}$ & 735 \\
\hline 13 & 20 & 1000 & 600 & $\begin{array}{l}15 . \\
8\end{array}$ & 5.1 & $\begin{array}{l}13 . \\
8\end{array}$ & 9.6 & 580 \\
\hline
\end{tabular}

\begin{tabular}{|c|c|c|c|c|c|c|c|c|}
\hline 14 & 20 & 1000 & 720 & $\begin{array}{l}17 . \\
6\end{array}$ & 5.6 & $\begin{array}{l}14 . \\
5\end{array}$ & $\begin{array}{l}10 . \\
7\end{array}$ & 730 \\
\hline 15 & 20 & 1000 & 840 & $\begin{array}{l}19 . \\
8\end{array}$ & 6.1 & $\begin{array}{l}15 . \\
2\end{array}$ & $\begin{array}{l}11 . \\
7\end{array}$ & 900 \\
\hline 16 & 20 & 1250 & 600 & $\begin{array}{l}18 . \\
2\end{array}$ & 5.5 & $\begin{array}{l}14 . \\
9\end{array}$ & $\begin{array}{l}10 . \\
6\end{array}$ & 710 \\
\hline 17 & 20 & 1250 & 720 & $\begin{array}{l}20 . \\
3\end{array}$ & 6 & $\begin{array}{l}15 . \\
8\end{array}$ & $\begin{array}{l}11 . \\
8\end{array}$ & 882 \\
\hline 18 & 20 & 1250 & 840 & $\begin{array}{l}22 . \\
9\end{array}$ & 6.5 & $\begin{array}{l}16 . \\
6\end{array}$ & 13 & $\begin{array}{l}109 \\
0\end{array}$ \\
\hline 19 & 24 & 800 & 600 & $\begin{array}{l}13 . \\
4\end{array}$ & 4.8 & $\begin{array}{l}13 . \\
6\end{array}$ & 9.4 & 450 \\
\hline 20 & 24 & 800 & 720 & 15 & 5.2 & $\begin{array}{l}14 . \\
3\end{array}$ & $\begin{array}{l}10 . \\
5\end{array}$ & 565 \\
\hline 21 & 24 & 800 & 840 & $\begin{array}{l}16 . \\
7\end{array}$ & 5.7 & 15 & $\begin{array}{l}11 . \\
5\end{array}$ & 700 \\
\hline 22 & 24 & 1000 & 600 & $\begin{array}{l}15 . \\
5\end{array}$ & 5 & $\begin{array}{l}14 . \\
6\end{array}$ & $\begin{array}{l}10 . \\
4\end{array}$ & 560 \\
\hline 23 & 24 & 1000 & 720 & $\begin{array}{l}17 . \\
2\end{array}$ & 5.5 & $\begin{array}{l}15 . \\
4\end{array}$ & $\begin{array}{l}11 . \\
6\end{array}$ & 694 \\
\hline 24 & 24 & 1000 & 840 & $\begin{array}{l}18 . \\
9\end{array}$ & 6 & $\begin{array}{l}16 . \\
2\end{array}$ & $\begin{array}{l}12 . \\
8\end{array}$ & 870 \\
\hline 25 & 24 & 1250 & 600 & $\begin{array}{l}17 . \\
6\end{array}$ & 5.4 & $\begin{array}{l}15 . \\
7\end{array}$ & $\begin{array}{l}11 . \\
5\end{array}$ & 680 \\
\hline 26 & 24 & 1250 & 720 & $\begin{array}{l}19 . \\
6\end{array}$ & 5.9 & $\begin{array}{l}16 . \\
8\end{array}$ & $\begin{array}{l}12 . \\
9\end{array}$ & 845 \\
\hline 27 & 24 & 1250 & 840 & 22 & 6.4 & $\begin{array}{l}17 . \\
6\end{array}$ & $\begin{array}{l}14 . \\
2\end{array}$ & $\begin{array}{l}106 \\
0\end{array}$ \\
\hline
\end{tabular}

Table 3.4: Final Cavity Dimensions and Volumes for all experiments

\subsection{Formation of Cavity and measurement of Dimensions.}

As the coal gasification reaction proceeds a cavity is created underground which consists of coal, char, ash, rubble, and void space. The dimensions of the cavity are of utmost importance because they are crucial in efficient usage coal resources and their recovery. The shape and rate of growth of this cavity will strongly impact reactant gas flow patterns, kinetics, temperature profiles, and so on.

The cavity evolution behind the injection well is defined as the backward length and it is less than height of the cavity which is measured in vertical direction and the width of the cavity which is measured in transverse direction at the injection point. The forward length of the cavity which is the distance from injection well to the end point of the cavity dome in the forward direction is larger than the height and the backward length. The convective flux of the reactant gases, towards the production well contributes to the additional growth of the cavity in the forward direction. The observed final cavity dome is nearly hemispherical in shape. The cavity shape is almost symmetric around the injection well. Figure 3.2.1 is a schematic pictorial representation of the final cavity shape, indicating the vertical, forward, backward and transverse directions. 

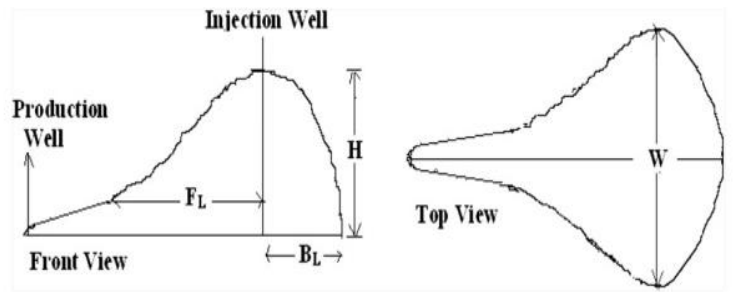

Figure 3.2.3: Diagram defining forward, backward lengths, height and width of the cavity

When the experiment is terminated, the coal block is separated from the refractory bricks for the post-burn examination and analysis. The cavity is covered by a thin aluminum foil and molten wax is poured in. After the wax solidifies, the block is broken in order to observe the final cavity shape. The final cavity dimensions in four directions (i.e. vertical, transverse, backward and forward) are measured. The cavity volume is calculated by dividing the wax weight by its density. The obtained volume is also confirmed independently through the water displacement technique. Figure 3.2.2\& 3.2.3 shows the cavity formed in coal block after completion of experiment and the final cavity shape respectively (Sateesh Daggupati et al., 2010).

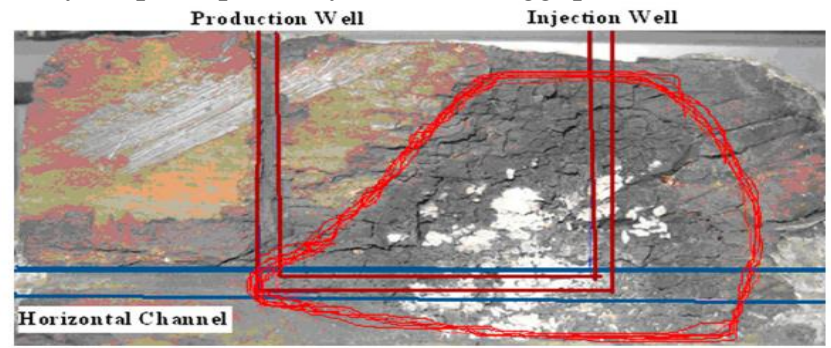

Figure 3.2.2: Cavity formed in coal block experiments $(\mathrm{Dw}=12 \mathrm{~cm}, \mathrm{Q}=600 \mathrm{ml} / \mathrm{min}, \mathrm{t}=6 \mathrm{~h}$ )

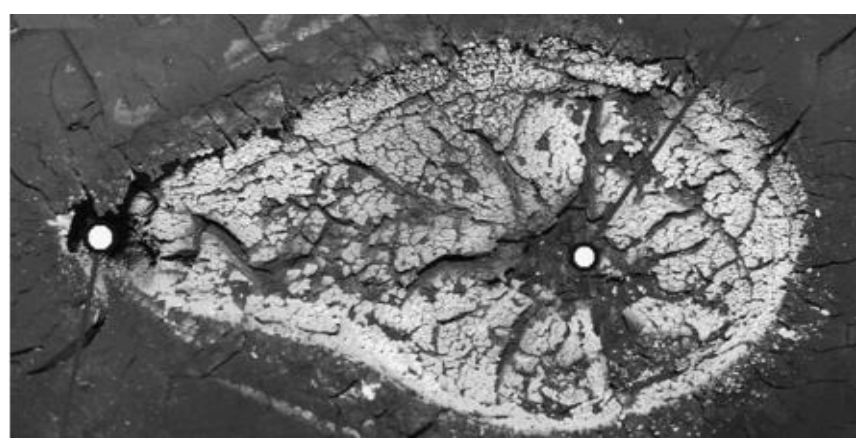

Figure 3.2.3: Final Cavity shape $(\mathrm{Dw}=12 \mathrm{~cm}, \mathrm{Q}=800$ $\mathrm{ml} / \mathrm{min}, \mathrm{t}=8 \mathrm{~h}$ )

\subsection{Basis and Aim of the work.}

Basis for the work was the laboratory scale studies done on combustion cavity growth in lignite coal blocks in the context of underground coal gasification by Sateesh Daggupati (Sateesh Daggupati et al., 2010).Prediction of the behavior of cavity growth from data obtained from various experimental trails using the differential evolution technique and deriving conclusions on the effect of different parameters on the growth of the cavity.

\section{VALIDATION OF EXPERIMENTAL RESULTS USING DIFFERENTIAL EVOLUTION.}

Differential Evolution (DE) is a parallel direct search method which utilizes NP (size of population)Ddimensional parameter vectors. The initial vector population is chosen randomly and should cover the entire parameter space. DE generates new parameter vectors by adding the weighted difference between two population vectors to a third vector. This operation is called Mutation. The mutated vector's parameters are then mixed with the parameters of another predetermined vector, the target vector, to yield the so-called trial vector. Parameter mixing is often referred to as crossover. If the trial vector yields a lower cost function value than the target vector, the trial vector replaces the target vector in the following generation. This last operation is called selection. Each population vector has to serve once as the target vector so that NP competitions take place in one generation.

$\mathrm{x}_{\mathrm{i}, \mathrm{G}}, \mathrm{i}=1,2, \ldots \mathrm{NP}$, where NP is the size of population

\subsection{Mutation}

For each target vector $\mathrm{x}_{\mathrm{i}, \mathrm{G}}, \mathrm{i}=1,2, \ldots \mathrm{NP}$, a mutant vector is generated according to

$\mathrm{v}_{\mathrm{i}, \mathrm{G}+1}=\mathrm{X}_{\mathrm{r} 1, \mathrm{G}}+\mathrm{F} .\left(\mathrm{X}_{\mathrm{r} 2, \mathrm{G}^{-}} \mathrm{X}_{\mathrm{r} 3, \mathrm{G}}\right)$.

With random indexes $r_{1}, r_{2}, r_{3} \in\{1,2, \ldots N P\}$, integer, mutually different and $F>0$. The randomly chosen integers $r_{1}, r_{2}$ and $r_{3}$ are also chosen to be different from the running index $\mathrm{i}$, so that NP must be greater or equal to four to allow for this condition. $F$ is a real and constant factor $\epsilon[0,2]$ which controls the amplification of the differential variation $\left(\mathrm{X}_{\mathrm{r} 2, \mathrm{G}^{-}} \mathrm{X}_{\mathrm{r} 3, \mathrm{G}}\right)$. Figure 1 shows a two-dimensional example that illustrates the different vectors which play a part in the generation of $\mathrm{v}_{\mathrm{i}, \mathrm{G}+1}$.

\subsection{Crossover}

In order to increase the diversity of the perturbed parameter vectors, crossover is introduced. To this end, the trial vector: $\mathrm{u}_{\mathrm{i}, \mathrm{G}+1}=\left(\mathrm{u}_{1 \mathrm{i} . \mathrm{G}+1}, \mathrm{u}_{2 \mathrm{i}, \mathrm{G}+1}, \ldots \mathrm{u}_{\mathrm{Di}, \mathrm{G}+1}\right)$

is formed where

$$
\begin{aligned}
u_{j i, G+1} & =\left\{\begin{array}{ll}
v_{j i, G+1} & \text { if }(\operatorname{randb}(j) \leq C R) \text { or } j=\operatorname{rnbr}(i) \\
x_{j i, G} & \text { if }(\operatorname{randb}(j)>C R) \text { and } j \neq \operatorname{rnbr}(i)
\end{array},\right. \\
j & =1,2, \ldots, D .
\end{aligned}
$$

$\operatorname{randb}(\mathrm{j})$ is the $\mathrm{j}^{\text {th }}$ evaluation of a uniform random number generator with outcome $\epsilon[0,1]$. $\mathrm{CR}$ is the crossover constant $\epsilon[0,1]$ which has to be determined by user. $\operatorname{rnbr}(\mathrm{i})$ is a randomly chosen index $€\{1,2 \ldots D\}$ which ensures that $u_{i, G+1}$ gets at least one parameter from $v_{i, G+1}$.

\subsection{Selection}

To decide whether or not it should become a member of generation $\mathrm{G}+1$, the trial vector $\mathrm{u}_{\mathrm{i}, \mathrm{G}+1}$ is compared to the target vector $\mathrm{x}_{\mathrm{i}, \mathrm{G}}$ using the greedy criterion. If vector $\mathrm{u}_{\mathrm{i}, \mathrm{G}+1}$ yields a smaller cost function value than $x_{i, G}$, then $x_{i, G+1}$ is set tou $\mathrm{i}_{\mathrm{i}, \mathrm{G}+1}$; otherwise, the old value $\mathrm{x}_{\mathrm{i}, \mathrm{G}}$ is retained [5] 


\subsection{Algorithm}

The following algorithm is followed in differential evolution, in order to solve any problem.

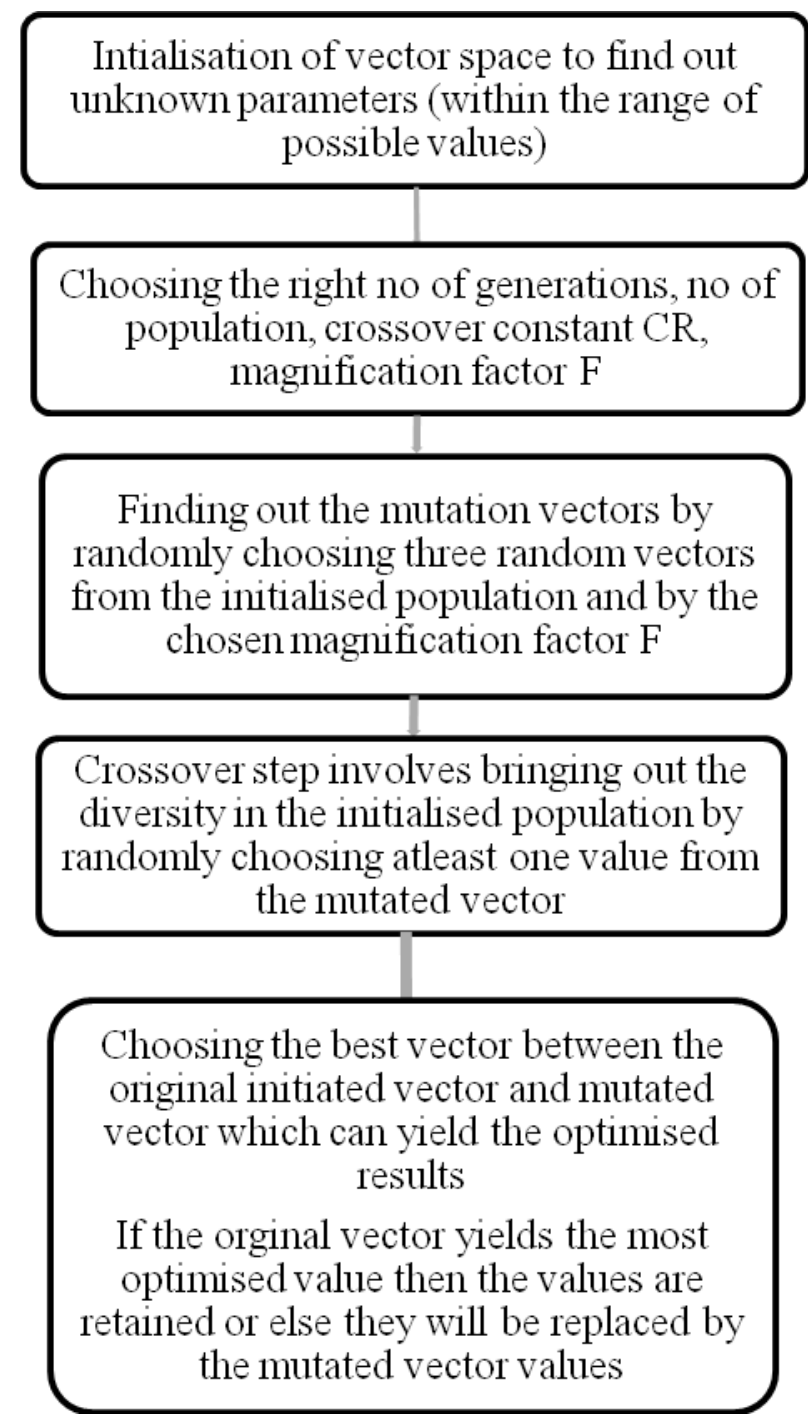

\subsection{Parameters Controlling Differential Evolution \\ 4.5.1 Population Size (NP)}

The influence of NP on the performance of DE is yet to be extensively studied and fully understood. Storm et.al have indicated that a reasonable value for NP could be chosen between 5D and 10D ( $\mathrm{D}$ being the dimensionality of the problem).

\subsubsection{Crossover Rate (CR)}

- The parameter CR controls how many parameters in expectation, are changed in a population member.

- For lower values of CR, a small number of parameters are changed in each generation

- Higher values of CR (near 1) cause most of the directions of the mutant vector to be inherited.

\subsubsection{Magnification Factor (F)}

- DE is much more sensitive to the choice of $F$ than it is to the choice of CR

- The upper limit of the magnification factor $F$ is empirically taken as 1 .

- As till date no benchmark function was successfully optimized with $\mathrm{F}>1$, it is usually avoided

\section{ANALYSIS OF CAVITY PROBLEM USING DIFFERENTIAL EVOLUTION.}

In order to estimate the cavity growth, a generalized correlation is proposed based on the data obtained from various experimental trails. The feed flow rate, distance between the injection and production wells and the operation time are the three independent parameters chosen. The dimensions of the cavity such as forward and backward lengths, height and width are chosen as dependent parameters.

The correlation is assumed to be in the form of D.V $=\left(a \times D^{b}\right.$ $\left.\times Q^{c} \times t^{d}\right)$, where $a, b, c, d$ are constants which are to be determined.

\subsection{Objective Function}

The objective function chosen in solving the current problem is the mean square error calculated between the experimental and correlational values of the parameters. The unknown parameters a,b,c\&d are optimized based on the mean square error.

\subsection{Mean Square Error}

Mean square Error measures the average of the squares of errors, i.e., the difference between the estimator and what is estimated.

Mean Square Error (MSE) $=\frac{\left(F_{\text {predicted }}-F_{\text {True }}\right)^{2}}{\text { No. of Predictions }}$

Where $F_{\text {predicted }}$ and $F_{\text {true }}$ are the predicted and true function values respectively

\subsection{Correlation Index}

The correlation coefficient of two variables in a data sample is a normalized measurement of how the two are linearly related. If the correlation index is close to 1 , it would indicate that the variables are positively linearly related and the parity plot falls almost along a straight line with positive slope. For -1 , it indicates that the variables are negatively linearly related and the scatter plot almost falls along a straight line with negative slope. And for zero, it would indicate a weak linear relationship between the variables.

Correlation Index $(\mathrm{CI})=\sqrt{\frac{1-\left(\mathrm{F}_{\text {predicted }}-\mathrm{F}_{\text {true }}\right)}{\sum\left(\mathrm{F}_{\text {predicted }}-\overline{\mathrm{F}}_{\text {predicted }}\right)^{2}}}$

where, $\bar{F}_{\text {predicted }}$ is mean value of NP predicted parameter values 


\subsection{Parameter values chosen to solve the problem}

To solve the present problem of evolution of cavity growth, the following parameters are chosen after various tuning experiments.

Table 5.4.1: Parameter Values chosen for the cavity problem

\begin{tabular}{|l|l|}
\hline \multicolumn{1}{|c|}{ Parameter } & Preferred values \\
\hline No of generations (NG) & 1000 \\
\hline Size of population chosen (NP) & 75 \\
\hline Crossover Constant (CR) & 0.8803 \\
\hline Magnification Factor (f) & 0.9 \\
\hline
\end{tabular}

\subsection{Pseudo Code}

Step-1: The first step is the random initialization of the parent population. Randomly generate a population of (say) NP vectors, each of dimensions. Values of the population are initialized randomly.

Step-2: Select three vectors from population and generate mutated vector $\mathrm{V}$ using equation (2).

Step-3: Recombine the each target vector $X_{i}$ with mutated vector generated in step- 2 to generate

a trial vector $\mathrm{U}_{\mathrm{i}}$ using equation (2).

Step-4: Check whether each variable of the trial vector is within range. If yes, then go to step-5

else make it within range using

$\mathrm{u}_{\mathrm{i}, \mathrm{j}}=2 * \mathrm{~s}_{\min , \mathrm{j}}-\mathrm{u}_{\mathrm{i}, \mathrm{j}}$, if $\mathrm{u}_{\mathrm{i}, \mathrm{j}}<\mathrm{s}_{\mathrm{min}, \mathrm{j}}$

$u_{i, j}=2 * s_{m a x, j}-u_{i, j}$, if $u_{i, j}>s_{\max , j}$

Step-5: Calculate the objective function values for vector $U$ $\& X$

Step-6: Choose better of the two (function value at target and trial point) for next generation.

Step-7: Check whether convergence criterion is met. If yes, then stop,or elsego to step3.

\section{RESULTS AND DISCUSSIONS}

\subsection{Predicated Correlations by Differential Evolution}

$\mathrm{F}_{1}=0.004 \mathrm{Dw}^{-0.1555} \mathrm{Q}^{0.642} \mathrm{t}^{0.670}$

$\mathrm{B}_{\mathrm{l}}=0.0406 \mathrm{Dw}^{-0.0863} \mathrm{Q}^{0.2655} \mathrm{t}^{0.5106}$

$\mathrm{W}=0.06 \mathrm{Dw}^{0.3203} \mathrm{Q}^{0.358} \mathrm{t}^{0.3119}$

$\mathrm{H}=0.0042 \mathrm{Dw}^{0.4253} \mathrm{Q}^{0.4176} \mathrm{t}^{0.5593}$

$\mathrm{C}_{\mathrm{v}}=0.0006 \mathrm{Dw}{ }^{-0.2557} \mathrm{Q}^{0.8859} \mathrm{t}^{1.3060}$

where $\mathrm{F}_{\mathrm{l}}, \mathrm{B}_{\mathrm{l}}, \mathrm{W}, \mathrm{H}, \mathrm{C}_{\mathrm{v}}$, Dw, Q, t are forward, backward lengths, width, height and volumes of the cavity, distance between the two wells, feed flowrate and time of operation respectively
6.2 Comparison of Errors.

Table 6.2.1: Errors predicted by Differential Evolution

\begin{tabular}{|l|ll|l|c|}
\hline Parameter & $\begin{array}{l}\text { \% Error } \\
\text { Daggupati } \\
\text { al.,2010) }\end{array}$ & $\begin{array}{l}\text { et } \\
\text { Predicted } \\
\text { by DE }\end{array}$ & $\begin{array}{l}\text { Standard } \\
\text { Deviation }\end{array}$ \\
\hline $\mathrm{F}_{1}(\mathrm{~cm})$ & 0.0174 & 0.0232 & 0.004101 \\
\hline $\mathrm{B}_{\mathrm{l}}(\mathrm{cm})$ & 0.0132 & 0.0021 & 0.007849 \\
\hline $\mathrm{W}(\mathrm{cm})$ & 0.0120 & 0.0031 & 0.006293 \\
\hline $\mathrm{H}(\mathrm{cm})$ & 0.0154 & 0.0072 & 0.005798 \\
\hline $\mathrm{C}_{\mathrm{v}}(\mathrm{cc})$ & 0.0282 & 0.0358 & 0.005374 \\
\hline
\end{tabular}

Table 6.2.2: Correlations for Cavity Growth and Correlation

\begin{tabular}{|l|l|}
\hline \multicolumn{2}{|c|}{ Index } \\
\hline $\mathrm{F}_{\mathrm{l}}(\mathrm{cm})$ & $\begin{array}{l}\text { Correlation } \\
\text { Index }\end{array}$ \\
\hline $\mathrm{B}_{\mathrm{l}}(\mathrm{cm})$ & 0.9979 \\
\hline $\mathrm{W}(\mathrm{cm})$ & 1.0000 \\
\hline $\mathrm{H}(\mathrm{cm})$ & 1.0000 \\
\hline $\mathrm{C}_{\mathrm{v}}(\mathrm{cc})$ & 0.9922 \\
\hline
\end{tabular}

\subsection{Optimized values for maximizing cavity volume}

Different inlet parameters conditions (within the range used for developing correlations) are taken, and optimized such that the conditions give a maximum cavity volume. The range of values of parameters taken in order to obtain the optimized conditions for coal block experiments are shown in Table 6.3.1

Table 6.3.1: Range of parameter values chosen for coal block experiments

\begin{tabular}{|l|l|}
\hline \multicolumn{1}{|c|}{ Parameter } & Range of Values \\
\hline Flow Rate $(\mathrm{ml} / \mathrm{min})$ & $800-1250$ \\
\hline Distance between wells $(\mathrm{cm})$ & $16-24$ \\
\hline Time of Operation $(\mathrm{min})$ & $600-840$ \\
\hline
\end{tabular}

The optimized parametric conditions for flow rate, distance between wells \& time of operation are 1250, 16 and 840 respectively which gives a volume of $1078.7 \mathrm{~cm}^{3}$.

On observing the results obtained from optimization it can be concluded that in order to maximize the volume of cavity, we should maintain maximum allowable flow rate possible, minimum permissible distance between the wells and maximum allowable time of operation.

\subsection{Effect of Distance between the injection and production well.}

Experiments at a fixed flow rate and operation time were conducted in order to study the effect of distance between the two wells on cavity shape and growth. The effect of distance between the wells on the cavity volume, forward length and backward length monotonically decrease with an 


\section{International Journal of Research in Advent Technology, Vol.7, No.4, April 2019}

E-ISSN: 2321-9637

\section{Available online at www.ijrat.org}

increase in the distance between the wells. On the other hand, cavity dimensions in the vertical and transverse directions increase with an increase in the distance between the two wells.
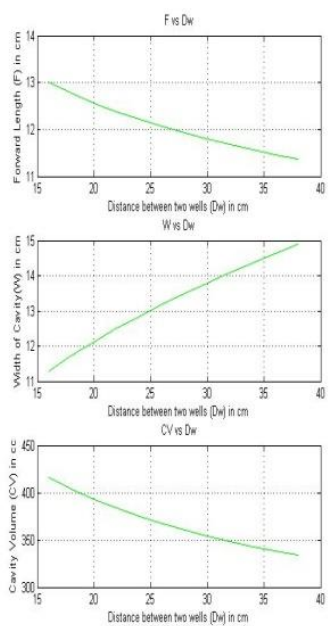

Figure 6.4.1: Effect of Dw on Cavity Growth

\subsection{Effect of Feed Flow Rate}

By increasing the feed flow rate of oxygen for a fixed distance between the wells and fixed operation time, the cavity grows rapidly in all the directions and hence its volume increases. Similar to the cavity volume and its evolution, the dimensions in all the four directions monotonically increase as the flow rate is increased.
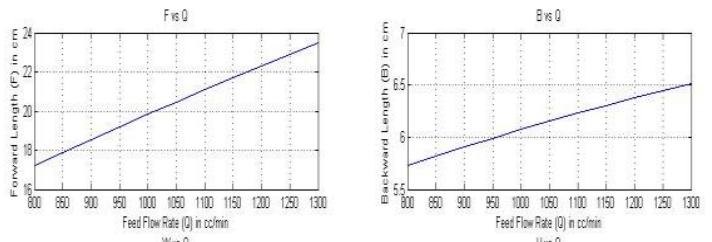

Who

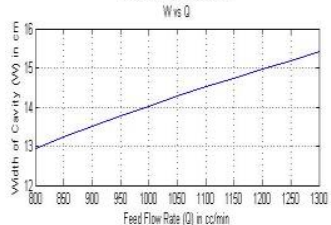
Niso
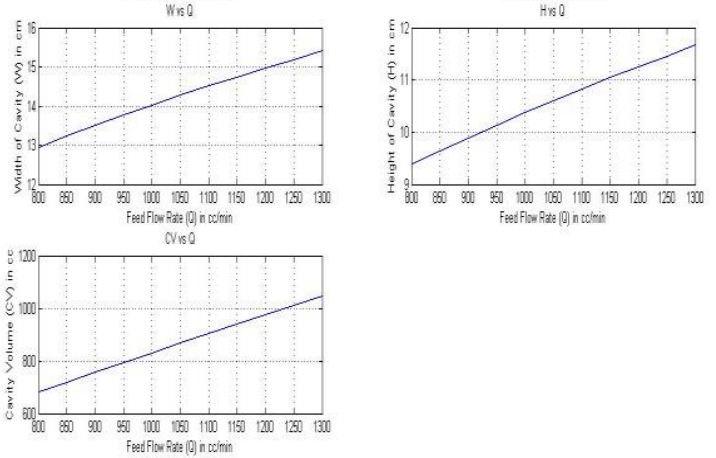

Feorflaw Pate (0) nodere
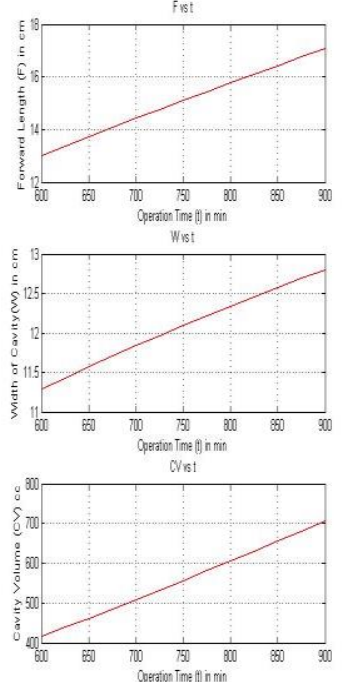

Figure 6.6.1: Effect of Operation time on Cavity Growth

6.7 Parity plots for experimental and predicted values.

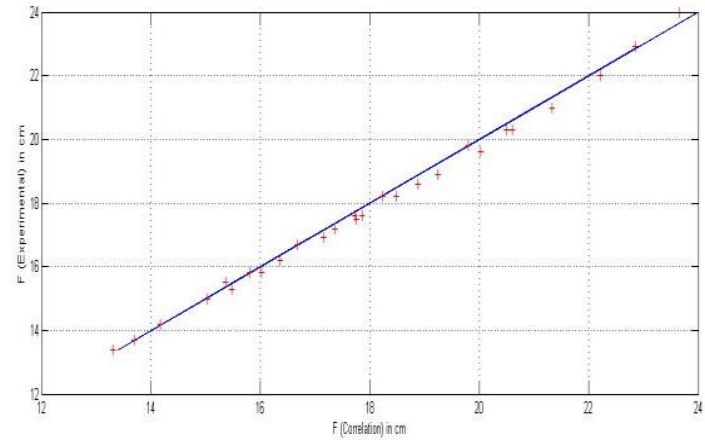

Figure 6.7.1: F (Experimental vs Correlation)

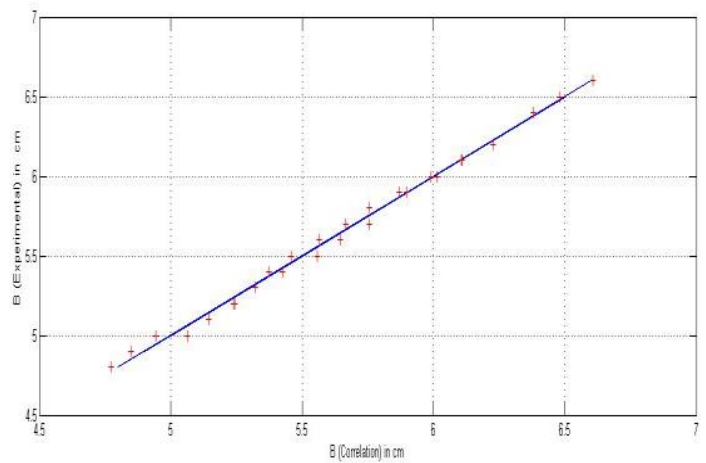

Figure 6.7.2: B (Experimental vs Correlation)

Figure 6.5.1: Effect of Q on Cavity Growth

\subsection{Effect of Operation Time}

The effect of operation time on cavity volume indicates that the cavity volume steadily increases with an increase in the operation time, as expected. The cavity growth in all the directions increases with an increase in the operation time. At a fixed flow rate and a fixed distance between the wells, the underground cavity reactor width and forward length would increase with an increase in the operation time. 
International Journal of Research in Advent Technology, Vol.7, No.4, April 2019

E-ISSN: 2321-9637

Available online at www.ijrat.org

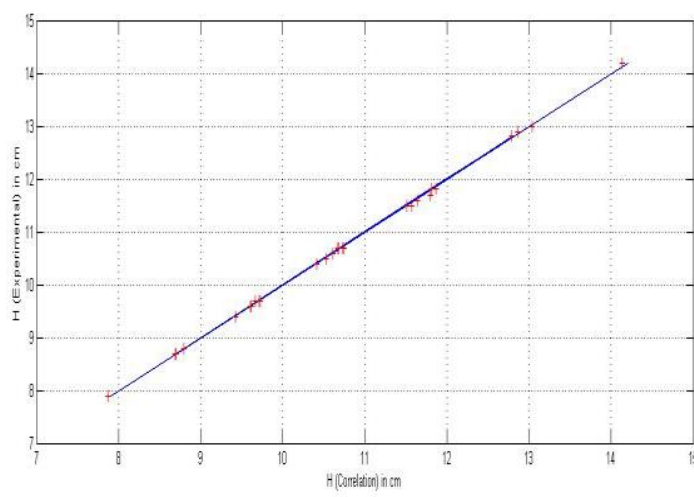

Figure 6.7.3: H (Experimentalvs Correlation)

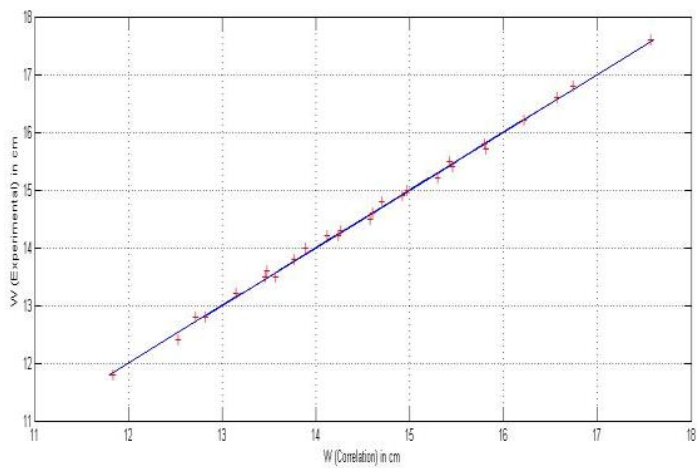

Figure 6.7.4: W (Experimental vs Correlation)

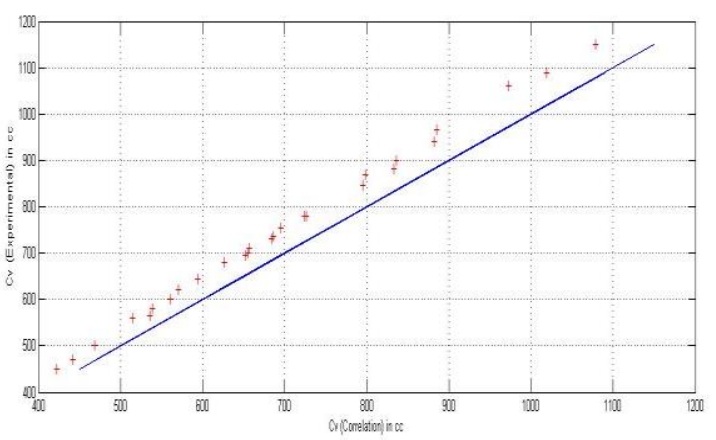

Figure 6.7.5: Cavity Volume (Experimental vs Correlation)

\subsection{Mean square error Vs Generation}

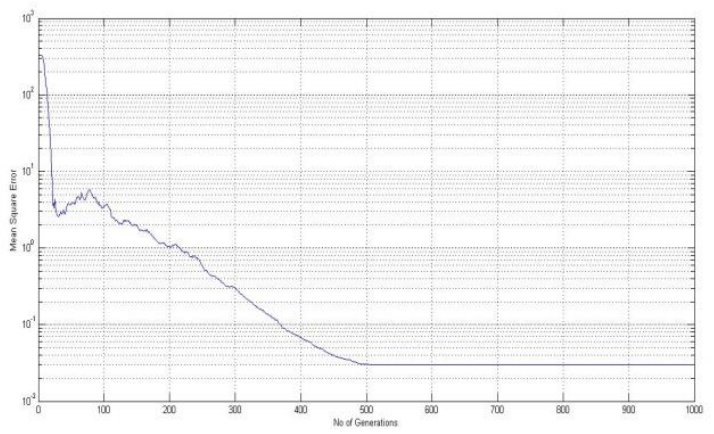

Figure 6.8.1: MSE vs NG of Forward Length

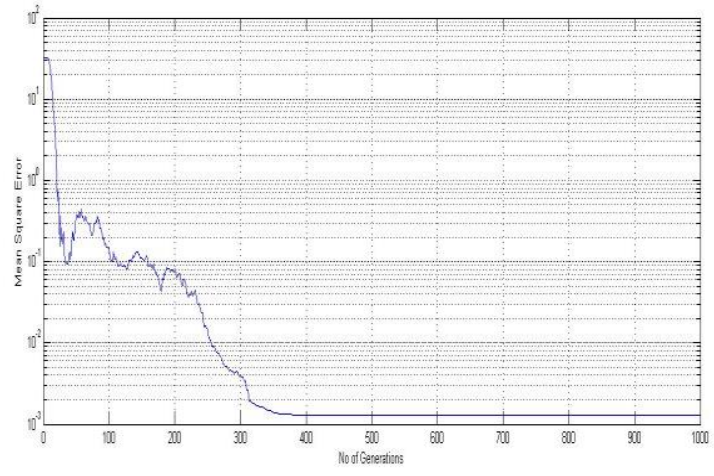

Figure 6.8.2: MSE vs NG of Backward Length

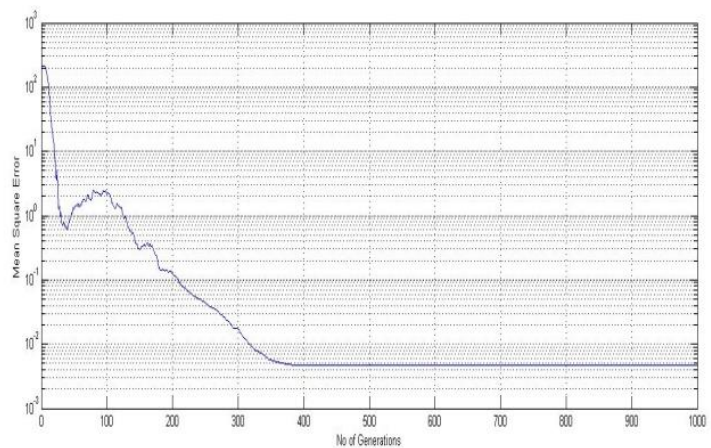

Figure 6.8.3: MSE vs NG of Width of Cavity

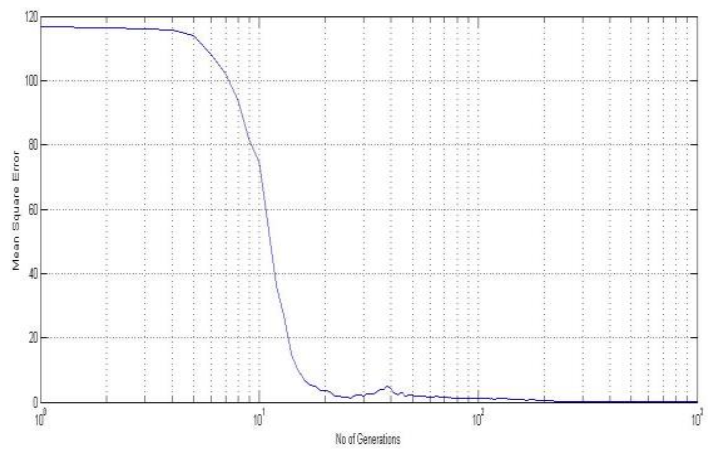

Figure 6.8.4: MSE vs NG of Height of Cavity

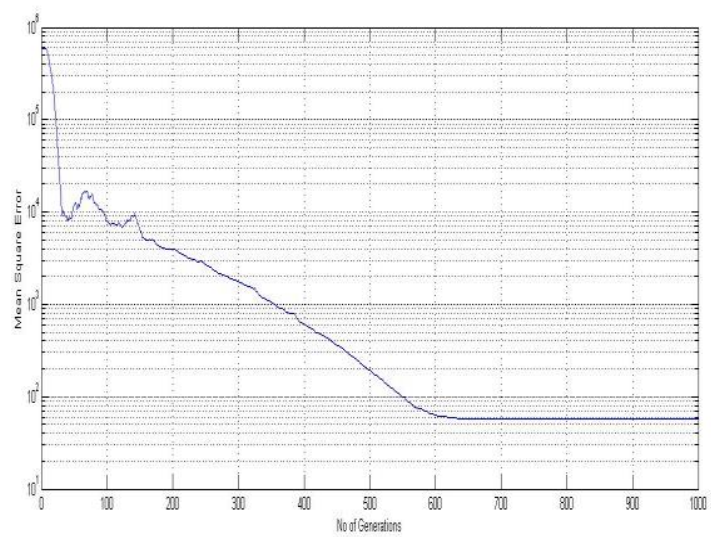

Figure 6.8.5: MSE vs NG of Cavity Volume

\subsection{Discussion}

The effect of different parameters like operation time, distance between two wellsand feed flow rate on the cavity growth has been predicted. Correlations which were better 
than the ones proposed by S Daggupati in his work (Sateesh Daggupati et al.,2010) were predicted \& proposed using the differential evolution technique. Variation of cavity dimensions with different parameters was presented in the form of graphs. Optimized conditions to yield maximum cavity volume were found and some conclusions were deduced. As we increase distance between the wells $\left(D_{w}\right)$, the cavity volume $\left(\mathrm{C}_{\mathrm{v}}\right)$ decreases for fixed time of operation $(t)$ and feed flow rate (Q). For fixed $t$, in order to maximize $C_{v}$, experiments are to be done at higher values of $D_{w}$ and Q.For fixed $\mathrm{Q}$, in order to maximize $\mathrm{C}_{\mathrm{v}}$, experiments are to be done at higher values of $D_{w}$ and $t$. For fixed $D$, for maximum cavity utilization $\mathrm{Q}$ should be increased to reduce the time of operation required. Parity plots are developed in order to check the closeness of the prediction with the experimental values. The parity plots are in close relationship with experimental values for all the parameters.

\section{Scope for Future Work}

Differential Evolution has also proved its usefulness in prediction in UCG, to find the effect of $D_{w}, Q \& t$ on cavity growth. In the similar way, the effect of temperature and prediction of syngas composition and its calorific value with respect to the changes in cavity parameters will be much more useful, to maximize the utilization of coal resources.

\section{Acknowledgement:}

We wish to express our gratitude to the entire faculty of Chemical Engineering and the Lab Assistants of ANITS, Visakhapatnam and RGUKT Basar involved in the completion of this work and making it successful. Our special thanks to Mr. Maruthi Rao, Department of Chemical Engineering, 2008 batch student.

\section{REFERENCES}

[1] AhadSarrafShirazi, CFD Simulation of Underground Coal Gasification, University of Alberta,Fall 2012

[2] A.W. Bhutto, A.A. Bazmi and G. Zahedi, Underground coal gasification: From fundamentals to applications, Progress in Energy and Combustion Science 39 (2013)

[3] Evgeny Shafirovich and Arvind Varma, Underground Coal Gasification: A Brief Review of Current Status, Ind. Eng. Chem. Res. Vol.48, 2009

[4] Pana, C., Review of underground coal gasification with reference to Alberta's potential; ERCB, 200910

[5] Rainer Storn, Differential Evolution - A Simple and Efficient Heuristic for Global Optimization over Continuous Spaces, Journal of Global Optimization 11: 341-359, 1997

[6] Sateesh Daggupati, Ramesh N. Mandapati, Sanjay M. Mahajani, Anuradda Ganesh,D.K. Mathur, R.K. Sharma, Preeti Aghalayam, Laboratory studies on combustion cavity growth in lignite coal blocks in the context of underground coal gasification,Energy 35 (2010)
[7] Sateesh Daggupati, Ramesh N. Mandapati, Sanjay M. Mahajani, Anuradda Ganesh,D.K. Mathur, R.K. Sharma, Preeti Aghalayam, Laboratory studies on cavity growth and product gas composition in the context of underground coal gasification, (2012)

[8] Sunggyu Lee, Gasification of Coal, Handbook of Alternative Fuel Technologies 